\title{
Research on the Reverse Innovation Recognition Mechanism of Core Enterprises in Industrial Innovation Network-Take the Power Industry of Yunnan Province as an Example
}

\author{
Guifeng Song \\ International Business School \\ Yunnan University of Finance and Economics \\ Kunming, China \\ 875563127@qq.com \\ Dongping $\mathrm{Yu}^{*}$ \\ International Business School \\ Yunnan University of Finance and Economics
}

\author{
Kunming, China \\ 247096657@qq.com
}

\author{
Sai Zhao \\ International Business School \\ Yunnan University of Finance and Economics \\ Kunming, China \\ 739457672@qq.com
}

\begin{abstract}
Innovation is the key to maintain the core competitiveness of an enterprise. Besides, innovation can make non-core enterprises become the core enterprise. Therefore, it is crucial for non-core enterprises and even core enterprises. This article uses the electric power industry in yunnan province in 2010-2016 patent cooperation data, combined with social network analysis methods, construct the non-core enterprises reverse innovation patent cooperation network model, through which the processing of centrality measure and analysis, and the construction of network model to identify its non-core businesses with reverse innovation trend. The results show that with the progress of time and economic progress, the network scale of patent cooperation is expanding, network structure is more complex, and the communication and connection between enterprises are increasingly close. However, from the overall perspective of yunnan power industry, there are very few enterprises with high intermediate center degree, indicating that most enterprises do not have the ability to control resources and technology.
\end{abstract}

Keywords-non-core enterprise; reverse innovation; recognition mechanism

\section{INTRODUCTION}

Innovation network is through partnerships with other organizations, organizations or individuals to establish a form in order to realize its innovation purpose [1]. It is the industry and the important way of the future industry innovation and development. Core enterprises are the core and leading enterprises in the industrial innovation network. These enterprises are large in scale and strong in technology. The non-core enterprise is the marginal enterprise in the industrial innovation network, which is smaller, less technical and less influential. The process of economic globalization has accelerated the emerging market, and the rise of developing countries has made more and more non-core enterprises independent innovation and gradually moved to the core enterprises. Early research on reverse innovation is mainly based on the national level of innovation. Innovation is the result of emerging countries or developing countries, and will further innovations into the market in developed countries, and even the whole world. As the economic globalization, emerging markets, emerging countries and developing countries have been rising, more and more reverse innovation has originated from non-core enterprises. The rise of huawei and xiaomi is the most obvious in real life.

Non-core enterprises in our country has experienced since the childhood, from weak to strong evolution, and in the development of national economy, increasing financial income, boosting employment has played an important role. The government will also be the development importance of small and medium-sized enterprises on the agenda, and successively formulated many policies and measures for their creating a favorable external survival and the development environment. But so far our non-core enterprises still face many problems in the process of its development. Such as small scale, insufficient investment in technology, narrow market, low profitability and short life. How to effectively improve non-core business development and management, promote small and mediumsized enterprise technology innovation ability, make the noncore business counter attack become core enterprise through innovation of non-core businesses and even the development of the national economy is of crucial importance.

The research on recognition mechanism is the key point in the research of reverse innovation in non-core enterprises. With the development of the innovation network theory, both the theoretical research of technological innovation and the

\footnotetext{
* Corresponding author
} 
theoretical research on the system innovation have paid more and more attention to the innovation, and the innovation network is the advanced form of the cooperation of industryuniversity-research [2]. Therefore, this paper takes the power industry of yunnan province as an example and uses the social network analysis method to carry out the non-core enterprise reverse innovation identification research on the patent cooperation data of the power industry on the basis of the concept and characteristics of reverse innovation of non-core enterprises. In this paper, non-core enterprises with reverse innovation trend are identified and analyzed through the enterprise network structure. The conclusion is of reference and reference to the development of non-core enterprises and national economy.

\section{LITERATURE REVIEW}

\section{A. Non-core Enterprise}

\section{1) Definition of non-core enterprise}

In previous research, the core enterprise's innovation ability and core competence has been at the center position. More interested in experts and scholars to study the core enterprise, so research of non-core enterprises is relatively small. Wang et al. through the case studied to define the non-core enterprises are those in collaborative innovation network scale is relatively small, simple structure, innovation ability is weak, in the downstream position, in the innovation network as the core enterprise to provide OEM, products, controlled by the core enterprise of the enterprise [3]. You et al. believes that noncore enterprises are controlled by the core enterprise of network center location, and provide OEM or supporting processing services for core enterprises. Non-core enterprise technology innovation ability is the key to integrate external innovation resources and ensure the success of innovation network [4].

\section{2) Research on non-core enterprises}

Tomlinson and Fai believed that non-core enterprise technology innovation capability can be effectively enhanced in a good, close and diversified collaborative innovation network [5]. Voudouris believes that the internal technical capability of non-core enterprises is an important determinant of the effect of technology investment [6]. Wang et al. combined with research situation of high and new technology industry in shenyang, the high and new technology industry innovation network of non-core enterprise technology innovation ability were analyzed, and concluded that technical level, knowledge absorption, development mode, enterprise control and policy environment all influence the non-core enterprise technology innovation ability to grow [3]. You et al. based on the new normal big background, the core of innovation network of enterprise technology innovation ability, influence factors and development trend of research development level, to accelerate the development of non-core enterprises become the core enterprise, promote the non-core business transformation, industrial upgrading and structural adjustment [4].

\section{B. Reverse Innovation}

\section{1) The concept of reverse innovation is defined}

The concept of "reverse innovation" was proposed in 2009 by Jeffrey Immelt, President of GE, and v. Govindarajan and Trimble $\mathrm{C}$ of the tuck school of business in the us. Crosi, Shen li and Ning zhong believe that this concept has not completely covered the essence of the concept of reverse innovation. Crosi believed that the main process is accomplished by the latedevelopment enterprise, which is the "reverse innovation" in the real sense [7], which is to emphasize the reverse process of innovation [8]. The traditional innovation model is that innovation originated in the developed countries and then introduced the innovation results to the developing countries. The reverse innovation model is that innovation originated in developing countries, and then spread the innovation results to other developing countries and even developed countries. Zhen argued that the reverse innovation refers to the low-end market big companies in emerging markets, integrate the existing advanced technology for the application of the existing technology, process innovation. As the technology improved, after the mature technology or product, then enter the mainstream high-end market value innovation mode of innovation, its essence is the value innovation [9]. Shan argued that the reverse innovation is a multinational company or emerging countries local companies use of indigenous innovation resources. It pioneered in developing countries. It will further innovation diffusion innovation mode of the developed countries and the world market. The core is the reverse. It focus on innovation direction of propagation [10]. This paper studies the reverse innovation is based on the developing countries of the enterprise level. Innovation is the result of non-core enterprises, through constant innovation gradually to the core enterprise. The innovation of reverse flow into the core enterprise and produces positive effect.

\section{2) Research on reverse innovation}

Govindarajan and Trimble believed that if the multinational companies in developed countries do not seize the opportunity of reverse innovation, emerging countries will take advantage of this innovative strategy to take the lead in preempting the market [11]. Wang pointed out that local innovation resources are the most important factors for the success of backward innovation [12]. Lim took the Nano car produced by tata of India as an example. Carefully analyzed and elaborated on how to use reverse innovation strategy to improve its technological innovation capability [13].

Maeda and Mori through the analysis of the photovoltaic industry in India, points out influence factors in the success of the enterprise reverse innovation technology backwardness factor. Also with top management's confidence in reverse innovation strategy, enterprise development and innovation ability, technology foresight, insight into the future market demand and match ability is closely related to the organizational culture [14]. Ray pointed out that there are three main factors influencing the success of reverse innovation: leadership and foresight of senior managers. Establish a modular production mode according to user requirements. Use local resources to build innovative clusters [15]. 
Zhen make full use of a large number of mature technology, imitation of classic products, technology innovation, combination of vertical integration in the industry of the effectiveness of the model by the company research and development, production, sales process analysis. Chinese enterprises can realize reverse innovation through the innovation model of "introduction - digestion and absorption innovation"[9]. Xu et al. summarized enterprise with leading technology backwardness potential difference smaller industries will get more chance to reverse innovation through the "small child prodigy" haier washing machine product to realize the process of reverse innovation research.

In the process of reverse innovation, backwardness enterprise easier to secure the support of indigenous innovation resources, through the open innovation strategy, technology and market management innovation contributes to the improvement of technology and innovation ability [16]. Li et al verified the zte corporation and innovative enterprise innovation driver stage in the process of formation characteristics through the analysis of zte company innovation and development process on the basis of the analysis of innovative enterprise formation theory. The study found that technology, market, management and organization innovation is the main power drive towards innovative companies to its success. And four total synergy innovation become zte company towards the basic characteristics of innovative enterprise after [17]. Xu et al. constructed the coma the realization of the enterprise reverse innovation path, technology innovation, market innovation, design innovation and organizational innovation four influence each other, to jointly promote the realization of enterprise reverse innovation using the grounded theory method to haier and mindray longitudinal study [18]. Xu at al. used multinational companies in emerging markets as the research object. It reversed innovation opportunities and supporting system for the ability to do the research. It put forward based on the diversified innovation opportunity.

It formated the competitive advantage of backwardness and enriched the ability to reverse innovation supporting system. Including: process niche oriented, product niche oriented and possess the ability of the mainstream market orientation needed [19]. $\mathrm{Xu}$ et al. found the coma enterprises should construct different in the different stages of development of innovation network through the longitudinal case study of haier group. It prompting reverse innovation implementation path is plural.

The unique advantages of the local market and the efforts to develop the technology learning and capability based on the innovation network are the key factors that influence the reverse innovation of the enterprise. The interaction and mutual influence of internal resources and external resources network drive the realization of reverse innovation [20]. Shan et al. from the two dimensions of technology and market to explore the growth pattern of huawei reverse innovation through the study of reverse innovation for the company in China. It put forward the internal innovation drive at various stages. In the primary stage of reverse innovation, the enterprise demand for emerging market environment, upgrade the ability of technology development and design. Reverse innovation should pay attention to is practical, to seek a balance between cost and performance [21].

\section{The Characteristics of Reverse Innovation in non-core Enterprises}

The characteristics of reverse innovation in non-core enterprises are mainly reflected in the following aspects: First, reverse innovation originated from non-core enterprises. In general, reverse innovation originates from core enterprises, and core enterprises are more innovative and capable, technical and resource support compared with non-core enterprises. However, with the continuous development of the economy and the continuous improvement of the market, non-core enterprises have gradually emerged and gradually moved to the core enterprises. The second is to re-invent and create new products based on the consumer market to produce products that satisfy customers and satisfy the market. Three is to establish a new and strong core competitiveness, develop new ways of thinking, build new economic growth platform, play to people's subjective initiative, enhance the innovation consciousness, and on the way of innovation more walk more far.

Existing research is less in the entire industry from the network structure of reverse innovation. This article in the past research, on the basis of reverse innovation in the perspective of network structure, using social network analysis method, starting from the measure of the network structure, and identifying the electric power industry in yunnan province has a reverse innovation trend of enterprises. It can strengthen the exchanges and cooperation between non-core businesses. To promote the technological progress of non-core enterprises reverse innovation and innovation ability.

\section{DETERMINATION OF RESEARCH METHODS AND MEASURES}

\section{A. The Research Methods}

Liu argued that social network analysis is a kind of social network structure and the analysis method of social relations. $\mathrm{He}$ tried to use tools, algebraic model technology of graph theory to describe relational schema, and explored the relationship between mode of the members or the influence of the overall structure. It is applicable to research group interaction and group structure. Social network analysis is made between the various actors of the quantitative analysis methods to analyze. Through the network diagram or a series of indicators reveals the characteristics of the network structure and the contact relationship between actors [22]. Yu believed that its core lies in the study of social phenomena and social structure from the perspective of "relationship" and is widely applied in fields such as sociology and information science [23]. This paper chooses Ucinet to deal with data. Because it can effectively deal with many different kinds of data and large number of nodes. And it can conduct centrality analysis of network structure.

\section{B. The Determination of the Measure}

This paper explores the network structure of reverse innovation in non-core enterprises. And mainly selects the 
centrality of point degree, proximity to center degree and middle center degree. "Centrality" is one of the research focuses of social network analysis. it is the structural location index of individuals or organizations. Evaluate whether a person or an organization is important in their social network or at the center of it.

\section{1) Point center degree}

The point center degree is mainly to calculate the close degree of a point connected with other points. And then determine which node is at the core of the network. If a node has the highest degree of degree. It is called the core location of the network, and has the status superiority and the privilege. The formula is:

$$
\begin{aligned}
\mathrm{CD}(\mathrm{ni})=\mathrm{d}(\mathrm{ni}) & =\Sigma \mathrm{jXij}=\Sigma \mathrm{j} \mathrm{Xji} \\
\mathrm{C}^{\prime} \mathrm{D}(\mathrm{ni}) & =\mathrm{d}(\mathrm{ni}) / \mathrm{N}-1
\end{aligned}
$$

Type: $\mathrm{CD}(\mathrm{ni}), \mathrm{C}^{\prime} \mathrm{d}$ (ni) is the point degree center. $\mathrm{Xij}$ is the value of 0 or 1 , and the connection strength between actor $\mathrm{j}$ and actor $\mathrm{i}$ is the number of people in this network.

\section{2) Middle center degree}

Middle center degree refers to the two points must go through this point want to establish a link between the media effect. It can consider this point in the important position. In the location of the point can be in the transfer of control right or wrong information to influence groups. If such a position holds, the more that this point has the very high betweenness. The more points if you want to connect you must through it. The center measure is the degree to which a person or organization controls resources. The formula is:

$$
\mathrm{CB}(\mathrm{ni})=\Sigma \mathrm{j}<\mathrm{k} \text { gjk }(\text { ni }) / \text { gjk }
$$

Type: the CB (ni) is the middle center degree. GJK is a shortcut between actors $\mathrm{j}$ and actors k, GJK (ni) is between actors $\mathrm{j}$ and actors $\mathrm{k}$ after the third actor I number of shortcuts.

\section{Data Collection, Processing AND ANALysis}

\section{A. Data Collection}

Wen believed that patent cooperation is a continuation and embodiment of social relations in the field of patent research and development. On the one hand, it is easier to establish cooperative relationships between individuals or organizations that are familiar with each other. On the other hand, through patent cooperation, partners can expand or consolidate existing social relationships. Patents contain complex social relations of cooperation. Cooperation between data can reflect the subject from the results of the analysis of social relations. Number of patent cooperation can directly reflect the relationship between the main body close degree. Patent cooperation network is a typical social relation network[24]. Through Chinese hownet advanced search patent cooperation data collected from yunnan province each industry. Because in addition to the electric power industry the rest of the industry number of patent cooperation is not outstanding. I choose electric power industry as the research object, through finishing the final data obtained patent cooperation 522 items. Therefore, this paper uses the patent cooperation data as the basis for analysis, taking the power industry of yunnan province as an example from 2010 to
2016, and from the perspective of network structure. The reverse innovation of non-core enterprises is investigated.

\section{B. Data Processing and Analysis}

\section{1) Network model construction}

Mentioned above is used to collect the electric power industry in yunnan province patent cooperation data. The patent cooperation data is transformed into a relational matrix. Based on social network analysis method, the construction of electric power industry in yunnan province using UCINET software industry cooperation network diagram. First, the relationship matrix between 2010 and 2016 is constructed in UCINET software. The Netdraw instruction is then executed in the program, which can automatically draw the network diagram based on the relationship matrix constructed. Finally, the manual layout is executed to improve the accuracy and sharpness of network graphs. The research results of network model visualization are shown in figure 1 .

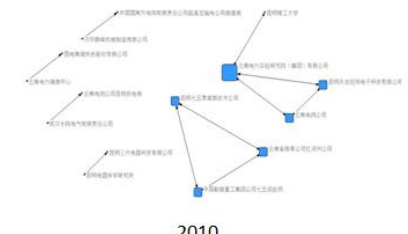

2010

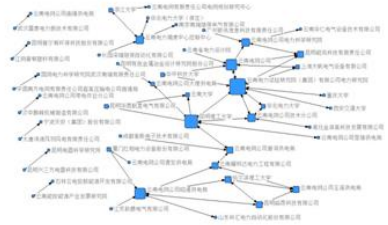

2014

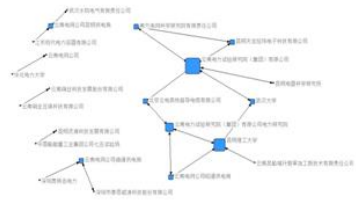

2011

2015

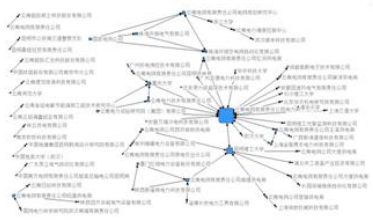

Fig. 1. Model of patent cooperation network of yunnan electric power industry

The attachment in figure 1 emphasizes the relationship between the nodes and shows the network scale of the patent cooperation of yunnan power industry. Take figure 1, 2010, 2011, 2014, 2015, four years of patent cooperation network diagram. Through the four years of patent cooperation network chart we can see that electric power industry in yunnan province in 2010-2016 of the patent cooperation scale unceasingly mature, the scope of the patent cooperation more widely. We can also be clearly observed from the network diagram of each node link between increased gradually. From 2010, 2011, just two more nodes reached 2014, and 2015. There was a link multiple nodes network diagram vein gradually obvious. The connectivity between all nodes increased year by year. Electric power industry in yunnan province in 2012-2014 patent cooperation network cohesion is more clear.

\section{2) Index analysis}

This paper identifies whether there is a reverse innovation trend of enterprises in the electric power industry in yunnan province based on the measurement of the centrality of the network. The measures can be calculated by UCINET software. 
As time goes on, the relationship between node is increasingly close. Network diagram is more intensive and scale. It shows that the enterprise cooperation and exchanges between the increasingly frequent, non-core business of reverse innovation momentum by leaps and bounds. It can identify the electric power industry in yunnan province in 2010-2016 has a reverse innovation trend of non-core businesses through the electric power industry in yunnan province obtained patent cooperation network graph and computing the centricity measure. Non-core enterprises with reverse innovation trend include: Kunming, yunnan power grid corporation power supply bureau, kunming university of science and technology, yunnan power grid corporation, yunnan power grid corporation branch, kunming Dali power supply bureau, yunnan power grid corporation technology to science and technology co., LTD., kunming, yunnan electric power dispatching control center and the China in turbine group survey design institute co., LTD., yunnan electric power company chuxiong power supply bureau, yunnan power grid corporation yuxi power supply bureau, yunnan power grid corporation qujing power supply bureau, yunnan power grid corporation pu 'er power supply bureau, yunnan power grid corporation power supply bureau in xishuangbanna, yunnan zhaotong power supply bureau, yunnan power grid company yaband of electric power engineering co., LTD., kunming ChengRun tai electronic technology co., LTD., yunnan power gridThe company's live operation branch. These companies have reverse innovation trend. But in the growth of this trend is not consistent. Some enterprises in some year trend is very big. Some enterprises are good reverse innovation trend for several years. The specific results are shown in figure 2 .

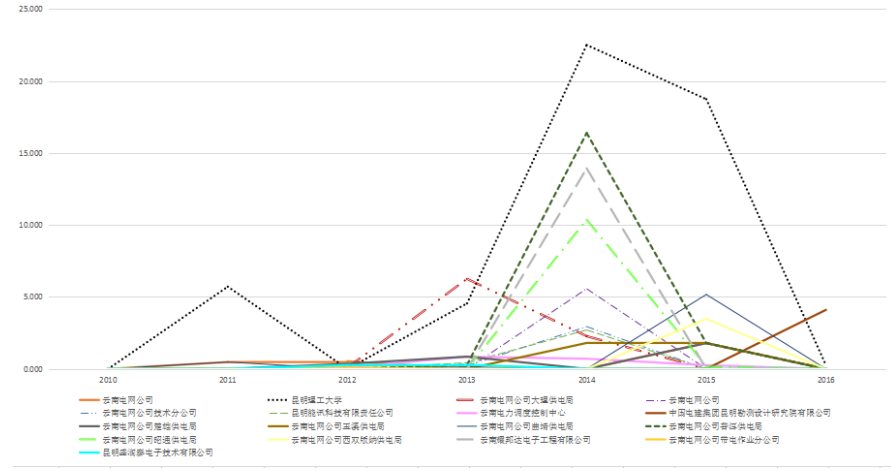

Fig. 2. Reverse innovation trend chart of non-core enterprises

we can determine the trend of reverse innovation of each enterprise in specific year. And we can clearly find out the growth rate and range of each enterprise in specific year from figure 2. It can be clearly seen from figure 2 that kunming university of science and technology is the most obvious unit of reverse innovation trend. In 2014-2015, this trend is the most obvious, maintaining the most central position from the whole. Yunnan power power supply bureau, yunnan yaobang da electronic engineering co., LTD., yunnan power grid company zhaotong power supply bureau has obvious reverse innovation trend in 2014. In 2013, Dali power supply bureau of yunnan power grid co., ltd. has a relatively obvious trend of reverse innovation. It has maintained the reverse innovation trend for several years, which is at the core of the overall situation. The qujing power supply bureau of yunnan power grid company and yunnan power grid company have obvious reverse innovation trend in 2015 and 2014 respectively. Yunnan power grid company xishuangbanna power supply bureau and China electric construction group kunming survey and design institute co., ltd. have a relatively small reverse innovation trend in 2015 and 2016 respectively. Yunnan power grid company kunming power supply bureau, yunnan power dispatch control center, yunnan power grid company chuxiong power supply bureau, although the reverse innovation trend is relatively small. But in 2010-2016 has maintained the status of progress. Technology branch, kunming yunnan power grid company can dispatch technology co., LTD., yunnan yuxi video company power supply bureau, kunming ChengRun electronic technology co., LTD., yunnan video game between the company has a weak trend of reverse innovation.

\section{CONCLUSION}

It can be observed that over time in the previous patent cooperation network diagram. The communication and cooperation between enterprises and enterprises become more and more closely. And cooperation between enterprises has become an inevitable trend. This article through to the electric power industry in yunnan province industry patent cooperation data processing and analysis. Electric power industry in yunnan province most enterprise point center degrees are lower. It shows that in the electric power industry network does not have any appeal. At the same time, the center degree is higher among enterprises are very few.

Even a lot of enterprise in the middle of the center degree zero. It shows that most companies do not have the ability to control resources and technology. Only a small number of enterprises have a higher ability to control resources and technology. In central measure and reverse innovation trend diagram to identify non-core enterprises with reverse innovation trend of non-core businesses. In future studies can be based on the results of the study, to identify the non-core enterprises to carry out empirical research. It devoted to the influence factors of its larger reverse innovation trend, the research of mechanism and its realization path. Under the background of economic globalization, in order to accelerate the pace of non-core enterprises reverse innovation. It need to strengthen exchanges and cooperation between various noncore enterprise. It need to enhance the activity of non-core business users. Timely release innovative information, communication and other enterprise in electric power industry platform to create a good communication atmosphere. Strengthen the cooperation between the enterprises.

\section{ACKNOWLEDGMENT}

This work was supported by Philosophy and Social Science Planning Program in Yunnan province, (the project number is YB2016064), supported by Apply Basic Research Projects to Projects in Yunnan province, (the project number is 2017FB101), and supported by National Natural Science Foundation Regional Projects, (the project number is 71764033), Thanks for all the sponsors. 


\section{REFERENCES}

[1] R.D. Fitjar, A. Rodrigue-Pose, "Firm collaboration and modes of innovation in Norway,” Research Policy, 1st ed, vol. 42, 2013, pp. 128138 .

[2] J. Chen, “Retrospective innovation: a new type of innovation, ” Technological progress and countermeasures, 8th ed, vol. 28, 2011, pp. 1-5.

[3] W. G. Wang, L. You, H. M. Zang, “Research on technology innovation capability of core enterprises in high-tech industry innovation network -a case study of shenyang city, " Technological progress and countermeasures, 2nd ed, vol. 34, 2017, pp. 45-50.

[4] L. You, W. G. Wang, “Evaluation on the technological innovation ability of core enterprises in innovation network," Exploration of economic problems, 7th ed, 2017, pp. 54-63.

[5] P.R. Tomlinson,F.M. Fai, "The nature of SME cooperation and innovation: a multi-scalar and multi-dimensional analysis," Int. J. Production Economics, 141th ed, 2013, pp. 316-326.

[6] I. Voudouris, S. Lioukas, M. Iatrelli, "Effectiveness of technology investment: impact of internal technological capability, networking and investment's strategic importance," Technovation, 7th ed, 2012, pp. 400414

[7] Corsi, S. "Reversing the international flow of innovation: how does Chinese market trigger reverse innovation?" Pisa: Advanced school Sant' s Annadi University Studies of Improvement, 2012.

[8] L. Shen, Z. Ning, "Research and prospect of enterprise reverse innovation based on emerging market," Research on technical economy and management, 12th ed, vol. 36, 2015, pp. 36-40.

[9] W. L. Zhen, "Research on reverse innovation mode - taking BYD Company Limited as an example," Technological progress and countermeasures, 5th ed, 2012, pp. 18-22.

[10] J. Shan, Y. Cheng, Q. Q. Li, "The research of reverse innovation and the future prospect," Technological progress and countermeasures, 21th ed, 2014, pp. 6-10.

[11] V. Govindarajan, C. Trimble, "Reverse innovation: a global growth strategy that could pre-empt disruption at home,? Strategy and Leadership, 5th ed, vol. 40, 2012, pp. 5-11.

[12] J. Wang, L. Xue, Z. Liang, "Multinational R\&D in China, from homecountry-based to host-country-based," Innovation: Management, Policy\&Practices, 2nd ed, vol. 14, 2012, pp. 192-202.
[13] C. Lim, S. Han, H. Ito, "Capability building through innovation for unserved lower and mega markets," Technovation, 12th ed, vol. 33, 2013, pp. 391-404.

[14] M. Maeda, K. Mori, "An inverse innovation for photo-voltaic (PV) industry," IEEE International Technology Management Conference, 2011.

[15] P. Ray, S. Ray, "Resource-constrained innovation for emerging economies: the case of the Indian telecommunications industry," IEEE Transactions on Engineering Management, 1st ed, vol. 57, 2010, pp. 144-156.

[16] Y. S. Xu, N. N. Xu, "Research on the success factors of "reverse innovation" in late-development enterprises -- taking the innovation of haier's "little child prodigy" as an example," Manage case studies and reviews, 2nd ed, vol. 6, 2013, pp. 147-155.

[17] J. G. Li, B. Y. Li, “The analysis of innovation-driven characteristics in the process of innovation-oriented enterprises in post-development enterprises -- taking zte corporation as an example," Technological progress and countermeasures, 2nd ed, vol. 31, 2014, pp. 78-82.

[18] N. N. Xu, Y. S. Xu, "Research on the reverse innovation of backward enterprises based on longitudinal case root analysis," Journal of management, 11th ed, vol. 12, 2015, pp. 1579-1587.

[19] Y. S. Xu, N. N. Xu, “Research on reverse innovation opportunity and capability support system -- case study of multinational companies in emerging markets,” Scientific research, 2nd ed, vol. 34, 2016, pp. 288 297.

[20] N. N. Xu, Y. S. Xu, “The collaborative evolution of reverse innovation of resources, innovation networks and late-development enterprises based on the longitudinal case study of haier group, " Management review, 6th ed, vol. 28, 2016, pp. 216-228.

[21] J. Shan, G. L. Dong, "Research on reverse innovation path of emerging market enterprises -- a case study from huawei," Technological progress and countermeasures, 2nd ed, vol. 34, 2017, pp. 87-93.

[22] J. Liu, “Overall network analysis handout: UCINET software practical guide, " Shanghai grange publishing house, Shanghai people's publishing house, 2009

[23] C. H. Yu, Q. J. Yuan, "Research on online bookstores in China based on social network analysis," Book intelligence, 20th ed, 2010, pp. 3640.

[24] F. F. Wen, "Research on patent cooperation model based on social network analysis," Intelligence magazine, 7th ed, vol. 32, 2013, pp. 119-123. 